\title{
الحرية في الإسلام أصالتها وأصولها
}

\section{* أحمد الريسوليث}

\section{مقدمة:}

إذا كان لكل شيء ضد، فللحرية أضداد متعددة؛ فالتسلط والاستبداد، والقهر والاستعباد، والاحتلال والاستغلال، والأغلال والقيود، والحواجز والحدود. وكذلك التسيب والتحلل، والفوضى والاستهتار. كلها أضداد

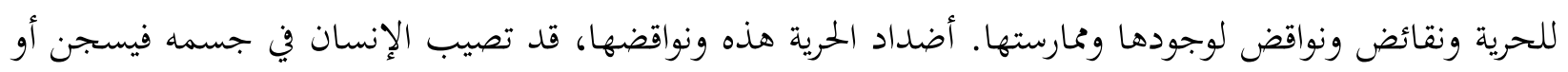
يعذب، أو في حياته فيقتل ويعدم، أو في سيادته فيسترق ويستعبد، أو في عزته وكرامته فيذل ويهان، أو في رزقه وماله فيمنع من كسبه أو من حرية التصرف فيه، أو في حرية القول والتعبير، فيمنع من الكلام، أو يعاقب إذا تكلم. كل هذه أحوال مقيتة بغيضة لا يرضاها حر لنفسه ولا لغيره، بل هي محنة ووبال على الإنسان فرداً وعلى الإنسان جنساً. غير أن أسوأ نواقض الحرية وأخطرها على الإنسان، هي تلك التي تصيبه في عقله وفكره وعلمه، وخاصة حينما تصبح حرية العقل وحرية الفكر وحرية الفهم مكبلة ومعاقة ذاتياً وداخلياً، وبنوع من الاقتناع والارتياح. ويوم جاء الإسلام، كان العرب -على سبيل المثال- يتمتعون بدرجة عالية من الحرية ومن العزة والكرامة؛ يتحركون ويتنقلون بحرية، ويتكلمون ويعبرون بحرية، ويتصرفون في مكاسبهم ومتلكاتم بحرية، ويحاربون أو يسالمون بحرية. ولكن حرية الفكر كانت عندهم مشلولة ومعطلة، أو على الأقل معاقة ومكبلة. ولم يكن ذلك من خارجهم ومن متسلط عليهم، بل كان من ذاقم ومن داخلهم، وبرضاهم وتمسكهم. مع العرب كان يعيش اليهود في تجمعات سكنية مستقلة، تتمتع أيضاً بقدر كبير من الحرية. وكانوا أصحاب تراث ديني وثقافي عظيم، من أهم ما كانت تملكه

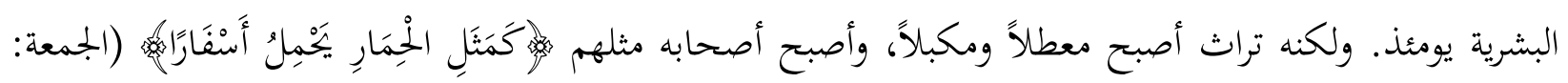
5). ولقد كان في مقدمة مقاصد البعثة المحمدية تحرير العقل والفكر، ورفع ما أحاط بكما من آصار وأغلال وقيود

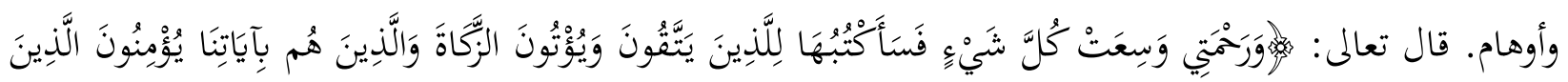

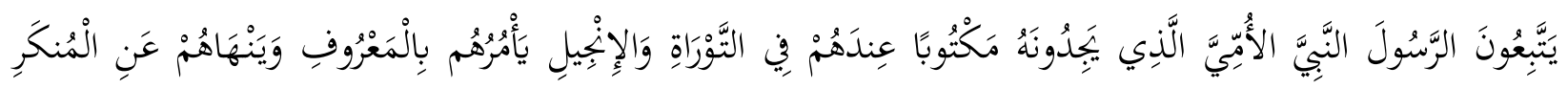

$$
\text { * * - مأستاذ أصول الفقه ومقاصد الشريعة - جامعة عمد الخامس - الرباط. }
$$




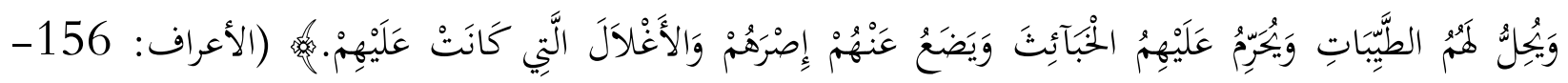

لقد جاء الإسلام رسالة تحريرية على كافة الأصعدة، وفي مقدمتها صعيد الفكر والفهم والعلم والتدين. وإذا كنا

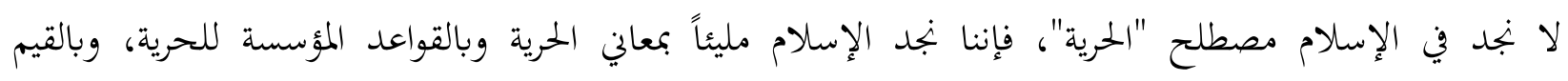

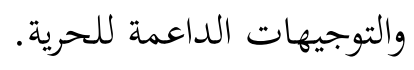

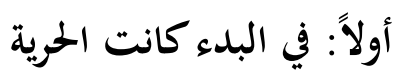

منا يلفت الانتباه في قصة خلق آدم كما يككيها القرآن الكريم، تلك العناية والمفاوة البالغة التي أحيطت بما

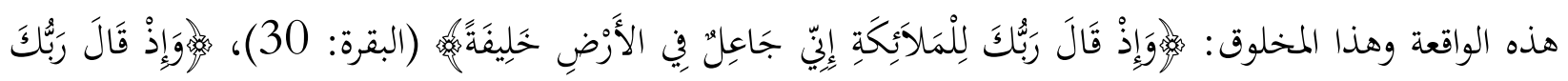

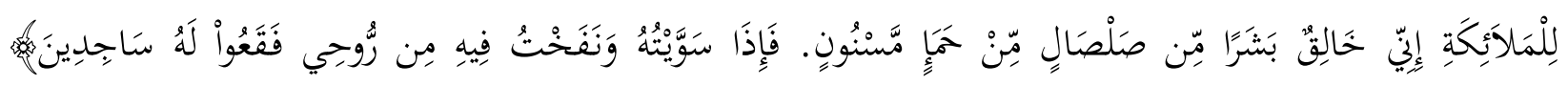

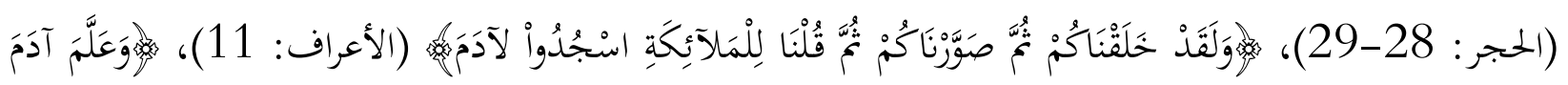

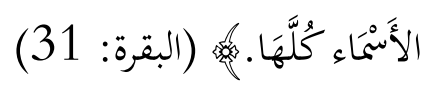

ولم تقف الحفاوة عند هذا الإعلان الإلمي الجليل، ولا عند تسمية هذا المخلوق خليفة، ولا عند تصويره وتسويته

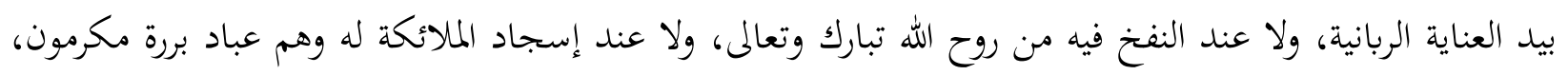

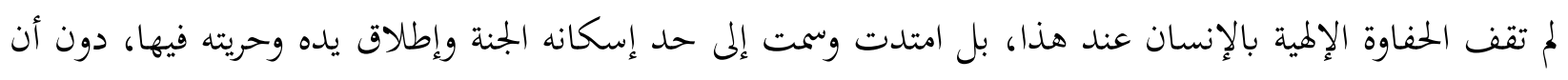

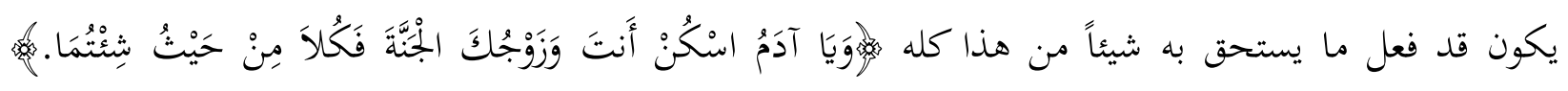

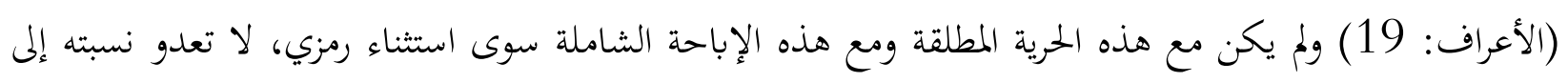
الجنة وما فيها، أن تكون كقطرة في بحر أو حبة رمل في صحراء.

وهكذا خلق الإنسان أول ما خلق عزيياً كريماً، وحراً طليقاً. وإذا كانت الأخطاء وعوارض أخرى متعددة قد

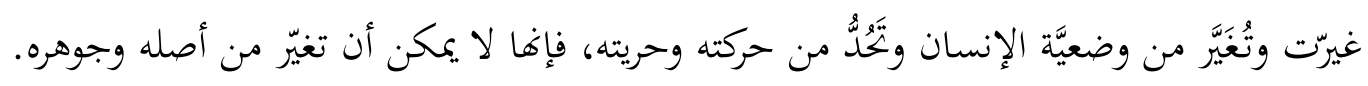

فكرامة الإنسان وحريته هي أصله وهي الأصل فيه. وهذا هو المعنى الذي ما فتئ العلماء والمفكرون ينصون

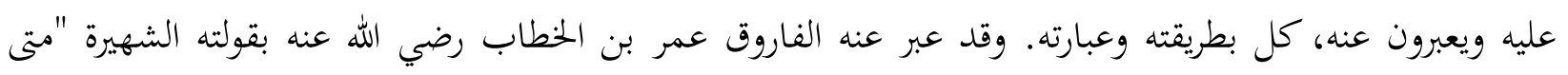


استعبدتم الناس وقد ولدقم أمهاقم أحراراً؟" ثم جاء الإعلان العالمي لحقوق الإنسان الصادر سنة 1948 عن الجمعية العامة للأمم المتحدة، ليكرر ويقرر هذا المعنى في مادته الأولى التي تقول: "يولد جميع الناس أحراراً متساوين في الكرامة والحقوق."

ولعل خير من تناول هذه المسألة من علماء الإسلام هو العلامة الشيخ محمد طاهر بن عاشور في كتابيه أصول النظام الاجتماعي في الإسلام، ومقاصد الشريعة. ففي الكتاب الأول اعتبر الحرية هي إحدى المصالح الأساسية والضرورية التي يقوم عليها المجتمع ويجب على ولاة الأمور تحقيقها وصيانتها. وبعد استعراضه لمفهوم الحرية الذي يتضمن معنيين هما: حرية الرقبة، وحرية التصرف، قال: "والحرية بكلا المعنيين وصف فطري نشأ عليه البشر، وبه تصرفوا في أول وجودهم على الأرض حتى حدثت بينهم المزاحة فحدث التحجير." 1

وهذا التقييد -أو التحجير - للحرية لا ينبغي اللجوء إليه إلا عند الضرورة ومن أجل دوافع ومصالح راجحة، يقول رحمه الله: "إن الحرية خاطر غريزي في النفوس البشرية، فيها (أي الحرية) ناء القوى الإنسانية من تفكير وقول وعمل، وبها تنطلق المواهب العقلية متسابقة في ميادين الابتكار والتدقيق. فلا يمق أن تسام بقيد إلا قيداً يدفع به عن صاحبها ضر ثابت أو يجلب به نفع."2 ويؤكد أصالة الحرية وفطريتها في موضع آخر بقوله: "والحرية بهذا المعنى حق للبشر على الجمملة، لأن الله لما خلق للإنسان العقل والإرادة وأودع فيه القدرة على العمل فقد أكنَّ فيه حقيقة الحرية وخوله استخدامها بالإذن التكويني المستقر في الخلقة."3

فابن عاشور يتجاوز ذلك النقاش والتأرجح الذي عرفه فلاسفة الحرية واللبرالية الغربيون حول أصل الحرية ومصدرها، هل هو الخلقة الأولى للأفراد وما فيها من نزوع إلى حرية التصرف واتباع هوى النفس وميولا، أم هو العقل والنظر العقلي، والعمل بمقتضاهما؟ وهي القضية التي يعرضها جون ديوي كما يلي: "كانت فكرة الحرية مرتبطة في تقاليد مذهب الأحرار -عند كل من الأمريكيين والإنجليز - بفكرة "الفردية"، أي بالفرد نفسه من حيث هو فرد. وكان هذا الارتباط وثيقاً وكثير الورود على الألسنة، حتى خاله الناس أمراً ذاتياً أصلياً. فكان الكثيرون يدهشون إذا ما سمعوا بأن أحداً يزعم أن للحرية مصدراً آخر وأساساً آخر غير طبيعة هذه الفردية نفسها. ومع ذلك فقد كان المأثور

$$
\begin{aligned}
& 2 \\
& 2 \\
& 3
\end{aligned}
$$


عند الأحرار في القارة الأوربية أن فكرة الحرية إنما ترتبط بناحية العقل والاستدلال. فالأحرار عندهم هم الذين يوجهون سلوكهم ويسيرون أمورهم بحسب ما يمليه عليهم العقل وحده، أما أولئك الذين يتبعون هواهم ويجرون وراء شهواقم وحسهم، فمحكومون بهذا الهوى وبتلك الشهوات والحواس، فهم ليسوا بأحرار."4

الرؤية الإسلامية لابن عاشور تتجاوز هذا التجاذب الثنائي في مرجعية الحرية ومعيارها، فكون الحرية صفة فطرية غريزية تلقائية، لا ينفي اعتمادها -تأصيلاً وممارسة- على العقل والنظر العقلي. وهذا ما يفسر لنا كون الحرية ولدت مع الإنسان، ولكنها أيضاً ولدت مقيدة من اللحظة الأولى، ولو أن تقييدها جاء في البداية رمزياً واستثنائياً. يقول ابن عاشور: "وقد دخل التحجير في بني البشر في حريته من أول وجوده، إذ أذن الله لآدم وزوجه -حين خلقا وأسكنا

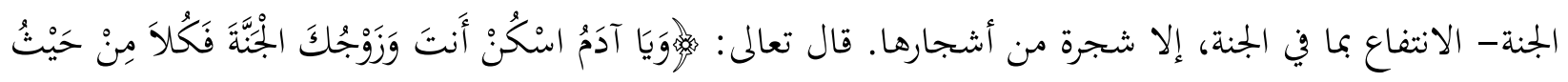

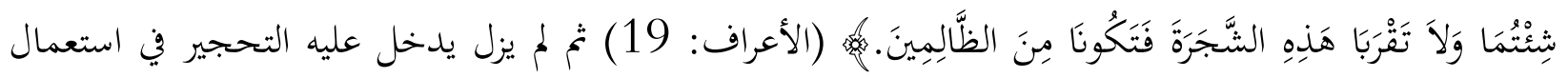
حريته بما شرع له من الشرائع والتعاليم المراعى فيها صلاح حاله في ذاته، ومع معاشريه، بتمييز حقوق الجميع ومراعاة

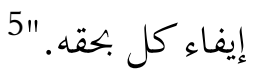

وهكذا تتأسس رؤية ابن عاشور إلى الحرية على أصالة مزدوجة متكاملة فيها: أصالة فطريتها الملازمة لكل فرد في خلقته، وأصالة مبدإ تقييدها وعقلنتها، باعتباره الشكل الوحيد الممكن لتحقيقها وإنباحها. يقول في مثال آخر عن حرية العمل: "وأما حرية العمل فإن شواهد الفطرة تدل على أن هذه الحرية أصل أصيل في الإنسان، فإن الله تعالى لما خلق للإنسان العقل وجعل له مشاعر تأتمر بما يأمرها العقل أن تعمله، وميز له بين النافع والضار بأنواع الأدلة، كان إذاً قد أمكنه من أن يعمل ما يريد مما لا يحجمه عنه توقع ضرر يلحقه. فكانت حرية العمل والفعل أصلاً فطرياً."6

وقد ألف الأستاذ محمد زكي عبد القادر كتاباً لطيفاً، يعد بمثابة استقراء لما قيل عن الحرية لدى مختلف الأمم والشعوب وعلى مدى عشرات القرون من الزمن. ويلخص المؤلف فكرة كتابه وثمرته بقوله في مقدمته: "وهذا الكتاب الذي أقدم له جمع أقوالاً في الحرية والكرامة الإنسانية، اختيرت من مختلف اللغات في الشرق والغرب: من العربية،

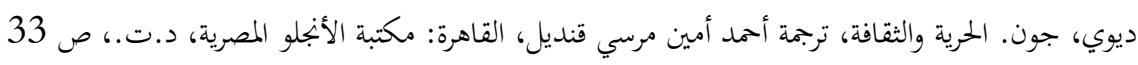
6 5 
والإنجليزية، والفرنسية، والإغريقية القديمة، واليونانية الحديثة، والإسبانية والإيطالية والألمانية، والأردية، والنرويية، وعلى الجملة من عدد كبير من اللغات التي يتحدث بها البشر، ومن مختلف العصور. فيها أقوال قيلت قبل الميلاد بألف سنة، وفيها أقوال قيلت منذ سنوات. وعلى طول ما يفصل بينها من الزمن لا تكاد بتح المعاني تغيرت، ولا حب الحرية والافتتان بها قل أو تحول. ويف هذا دليل على أن الحرية والكرامة الإنسانية ليستا شيئين ينموان بنمو الإنسان، ولكنهما شيئان ولدا معه وأحس بكما وكافح من أجلهما وأراق دمه في سبيلهما؛ قد يتطور مدلولهما ويتقدم ويتسع،

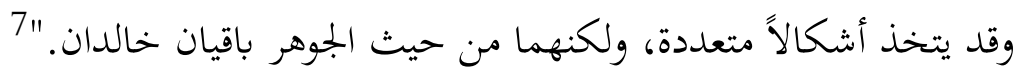

وإذا كانت الحرية صفة فطرية من صميم خلقة الإنسان ومن صميم مؤهلاته الأولية، فمن الطبيعي أن يجعل الإسلام -وهو دين الفطرة- هذه الحقيقة أساساً مرجعياً في تشريعاته وأصوله التشريعية. ولتوضيح ذلك أعرض فيما بعد بعض الأصول الإسلامية المترجمة لمبدأ أصالة الحرية.

\section{ثانياً :الإباحة الأصلية:}

من القضايا التي يتطرق إليها ويناقشها عامة الأصوليين قضية حكم الأفعال والأشياء قبل ورود الشرع، أي في حالة عدم وجود شرع، وكذلك حكم الأفعال والأشياء التي سكت عنها الشرع بعد وروده، فلم يخصها بحكم. ويحكي الأصوليون في هذه المسألة ثلاثة أقوال مشهورة، مع قول رابع يمكن إضافته وتمييزه عند التمحيص والتدقيق.

القول الأول لجمهور الأصوليين، وخاصة منهم الحنفية، وعامة الفقهاء. وهو قول الظاهرية ومفاده أن كل ما لم يرد فيه شرع، أو لم يخصه الشرع بحكم، فالأصل فيه أنه مباح. وهذا ما يقصدونه بعبارة "الأصل في الأشياء الإباحة" أو "الإباحة الأصلية".

القول الثاني، وهو لبعض المعتزلة وبعض الأشاعرة، ويرون أن الأصل في الأشياء هو الحظر والمنع، حتى يرد دليل الإباحة. 
القول الثالث، وهو لكثير من الأصوليين المتكلمين، من معتزلة وأشاعرة، وهو القول بالوقف، باعتبار أن كلا من الإباحة والتحريم حكم شرعي وحيث لا دليل ولا خطاب من الشرع فلا حكم، أي لا تحريم ولا إباحة، وإنما نتوقف عن إصدار حكم في المسألة وفروعها التطبيقية.

أما القول الرابع، وهو قلما يذكر، فهو التفريق بين الأشياء النافعة، والأشياء الضارة. فالأصل في الأولى الإباحة، والأصل في الثانية التحريم. وبهذا قال الفخر الرازي، 8 وتبعه بعض المتأخرين.

وأنا أريد أن أقف عند القولين الأول والثاني. فالأول مع الحرية وأها هي الأصل، والثاني على العكس. أما القولان الآخران فيؤلان في النهاية إلى الوفاق العملي مع القول الأول. فالقول بالوقف، هو بجرد امتناع من إصدار "حكم شرعي" بالإباحة أو الحظر. والنتيجة العملية أن الناس في هذه الحالة يبقى أمرهم بيدهم، فمن شاء أقدم ومن شاء أحجم. فالقول بالوقف لا يمكن أن يتحول إلى تحفظ وتعرض، وإلا التحق بالحظر والتحريم، وإذا ترك الناس لشأغم فتلك هي الإباحة عملياً، وإن لم يصدر بشأفها "حكم شرعي". فأصحاب هذا القول يختلفون مع القول الأول نظرياً لا عملياً، فهو خلاف كلامي ليس إلا. وأما القول الرابع، فهو وإن كان فيه تدقيق وجيه وله سنده في نصوص الشرع، فهو بمثابة ذكر الاستثناء عند ذكر القاعدة. ذلك أن ما خلق الله تعالى من أشياء كله في الأصل مفيد ونافع، والضرر فيه عارض وشاذ. فإذا قررنا أن الأصل في المنافع الإباحة، فكأننا قررنا أن الأصل العام في الأشياء هو الإباحة، وهذا هو القول الأول. وإذا قررنا أن الأصل في المضار التحريم، فكأننا قررنا أن التحريم وارد على سبيل الاستثناء في الأشياء الضارة ضرراً راجحاً، وهي ذات نسبة ضئيلة بجانب ما في الكون والحياة من منافع وفوائد

وأعود للقول الأول لأوضحه وأوضح أهم مستنداته، وهو القول بأن الأصل العام في الأشياء والأفعال هو الإباحة، أي حرية التصرف. يستند هذا القول إلى جملة من الآيات والأحاديث.

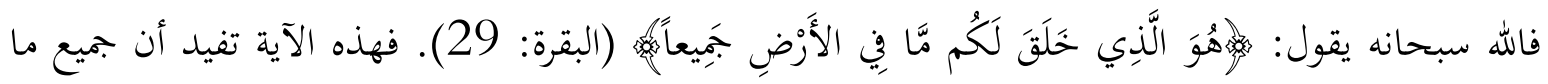

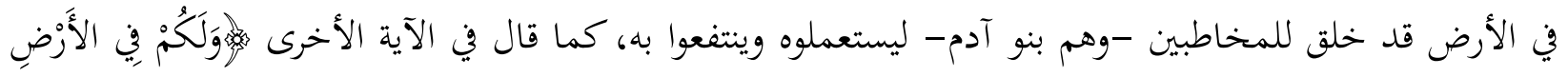

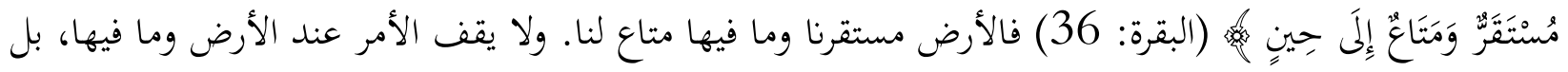

8 8 الرازي، فخر الدين. الخصول من علم الأصول، تحقيق طه جابر العلواني، الرياض: جامعة الإمام محمد بن سعود الإسلامية، جزء 2، ص 541 


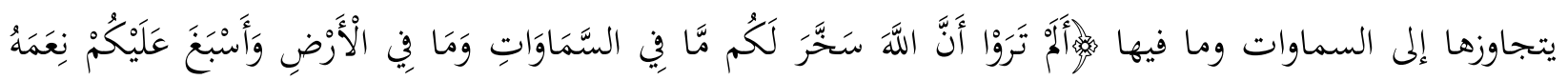

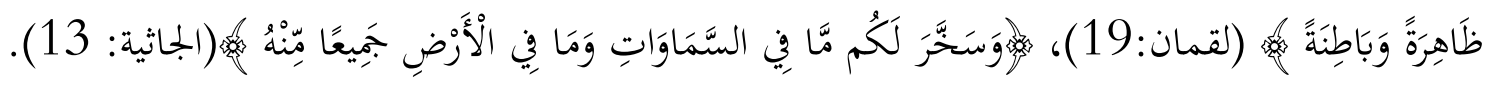

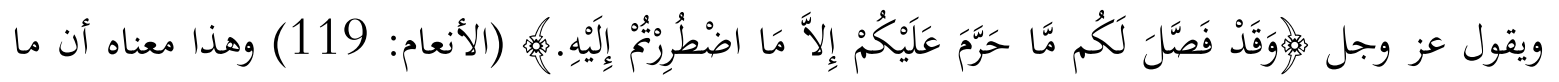
حرمه الله تعالى هو ما ذكره ونص عليه وفصل القول فيه. ومعناه أيضاً انتفاء التحريم عما سواه. وقد جمع ابن حزم

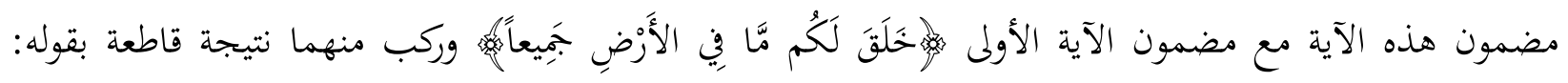
"فصح بماتين الآيتين أن كل شيء في الأرض وكل عمل فمباح حلال إلا ما فصل الله تعالى تحريمه باسمه، نصاً عليه في القرآن وكلام النبي صلى الله عليه وسلم."

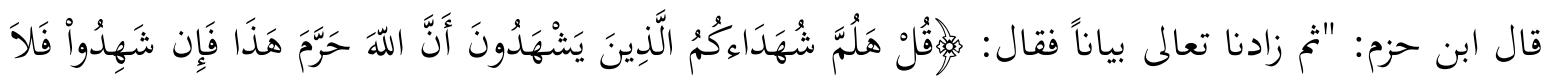
تَشْهَهْ مَعَطُمْهِه. (الأنعام: 150)، فصح بنص هذه الآية صحة لا مرية فيها أن كل ما لمَ يأت النهي فيه باسمه من عند

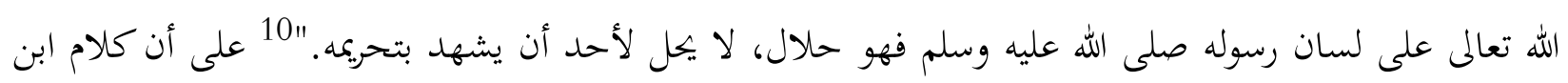
حزم رحمه الله -مع متانته وقوة منطقه- يحتاج إلى شيء من الاستدراك والتدقيق في بعض ألفاظه.

وقد استدل القائلون بالإباحة الأصلية كذلك بعدة آيات نصت على إباحة الطيبات وما خلقه الله من زينة ورزق، وتنكر على من حرموا ما خلق الله لعباده، كما تنص بعض هذه الآيات -وهو محل الاستدراك على كلام ابن

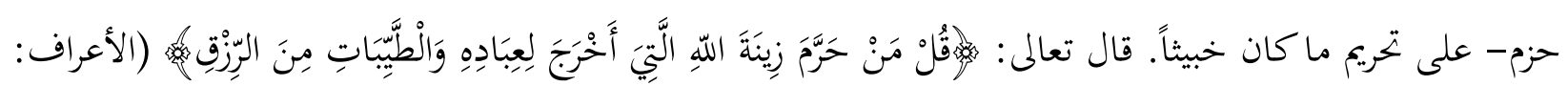

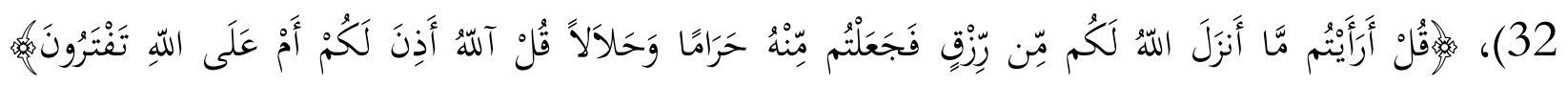

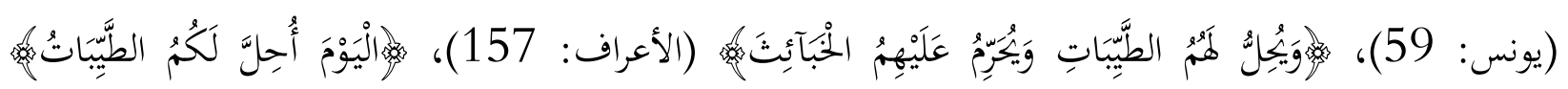

فكل هذه النصوص تفيد صراحة وقطعاً أن كل ما كان زينة وطيباً، فحكمه الأصلي هو الحل والإباحة، ولا يتعلق به التحريم إلا عرضاً ولأسباب عرضية ليست ذاتية. ومقابل هذا، فإن ما كان خبيثاً فحكمه الأصلي هو التحريم، سواء كان مما فصل الله تعالى ومما ذكره باسم، أو لم يكن كذلك وعرفناه بصفته (الخبث). فهذا هو

$$
9 \text { 10 } 10
$$


الاستدراك الذي لابد منه على كلام ابن حزم المتقدم، حيث يلح أن الحرام هو فقط ما ذكر الله تخريمه بالاسم. والحقق أن الله تعالى حرم أشياء بصفتها، فمتى ثبتت تلك الصفة (الخبث والضرر) ثبت التحريم. ونبقى معه في أن كل ما لم يتصف بالخبث فحكمه الإباحة وحرية الاستعمال والتصرف.

من تطبيقات القاعدة وآثارها: قاعدة "الأصل في الأشياء الإباحة"، تعني أن الإنسان حر مسموح له بالتصرف في نفسه وفيما يزدحم به هذا الكون من خيرات وكائنات ومنافع وإمكانات. فهذا هو الأصل المعتمد حتى يأتي استثناء شيء ممن له الأهلية وله الحق في ذلك، أو حتى يظهر فساد شيء ويثبت خبثه وضرهه. وهذه القاعدة قبل أن تحرر الإنسان في سلوكه وتصرفه، تحرره في إيمانه وضميره. فهو بفضلها يعلم ويطمئن أن ما لم يرد فيه تحريم ولا تقييد، وكان له فيه رغبة ومصلحة فهو له، ولا حرج فيه ولا خوف منه، وأن تصرفه ذلك حلال سائغ، فضلاً من الله ونعمة.

ومن هنا ندرك ذلك السر والخيط الرابط بين تحليل الطيبات وتحريم الخبائث من جهة، وإزالة الأغلال والآصار

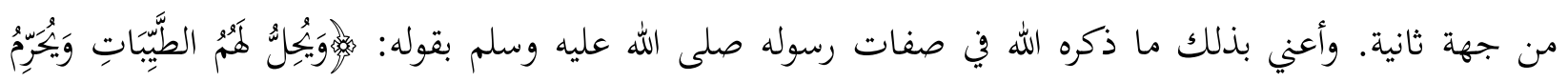

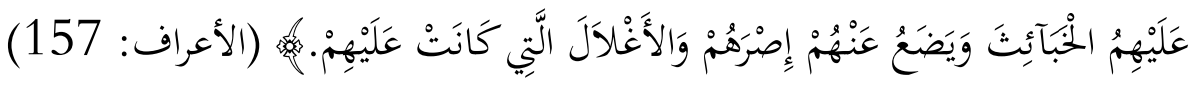

فالمؤمن إذا أصبح شاكاً خائفاً من شبح التحريم والإثم حيثما فكر وقدر، وكلما هم وعزم، وأينما تحرك واتبهه، لمجرد أن كل ما ليس منصوصاً على إباحته فهو حرام، أو يحتمل أن يكون حراماً، أو قيل أنه حرام، أو فيه شبهة الحرام. هذا المؤمن قد يدخل في أزمة إممان وضمير، قبل أن يدخل في أزمة تصرف وتدبير.

ومن المجالات التي تحتاج إلى استحضار هذه القاعدة فيها، من أجل رفع الضيق والحرج والحيرة عن الناس، وحتى

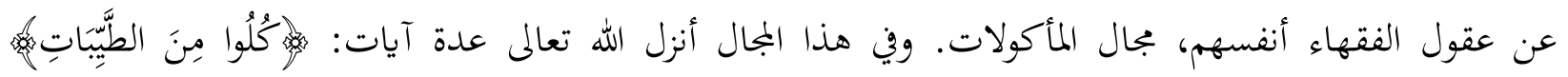

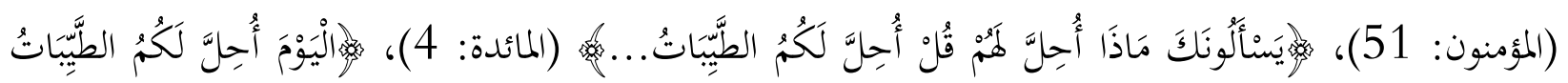

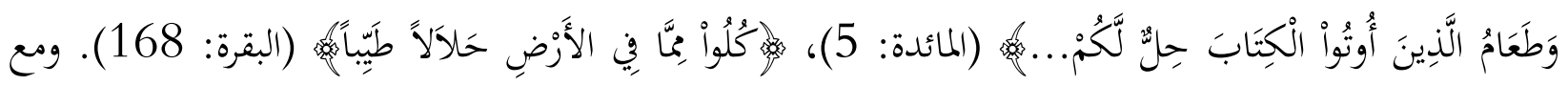
هذا كله نجد خلافات ونزاعات فقهية لا تنتهي في كثير من الأطعمة والحيوانات -أحلال هي أم حرام- مما يمكن رده إلى هذه الآيات وحسمه هها بلا تردد. فكل ما كان طيباً -أي يستطيبه الناس وينتفعون به- فهو حلال بلا تردد. 
ولتوضيح هذه المسألة بكفاءة وجدارة، أستسمح القارئ الكريم في نقل نص مطول للعلامة المجدد محمد الطاهر

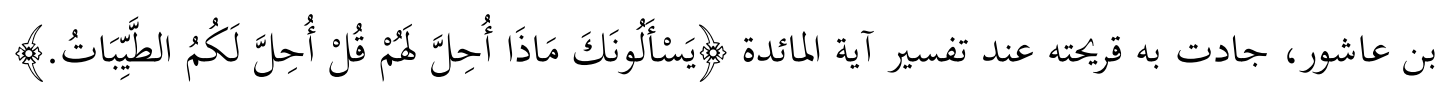

فبعد أن ذكر طرفاً من اختلاف الفقهاء في تحديد معنى الطيبات ومعيار تحديد ما هو طيب وما ليس بطيب، حيث أرجع بعضهم ذلك إلى عادات العرب وأذواقهم، وبعضهم أرجعه إلى المتحضرين من الناس دون أهل البداوة والبدائية، بعد ذلك قال رمه الله: "وفيه من التحكم في تحكيم عوائد بعض الأمة دون بعض ما لا يناسب التشريع العام، وقد استقذر أهل الحجاز لحم الضب بشهادة قوله -صلى الله عليه وسلم- في حديث خالد بن الوليد: "ليس هو من أرض قومي فأجدني أعافه" ومع ذلك لم يحرمه على خالد.

والذي يظهر لي: أن الله قد ناط إباحة الأطعمة بوصف الطيب فلا جرم أن يكون ذلك منظوراً فيه إلى ذات الطعام، وهو أن يكون غير ضار ولا مستقذر ولا مناف للدين، وأمارة اجتماع هذه الأوصاف أن لا يحرمه الدين، وأن يكون مقبولاً عند جمهور المعتدلين من البشر، من كل ما يعده البشر طعاماً غير مستقذر، بقطع النظر عن العوائد والمألوفات، وعن الطبائع المنحرفات. ونحن نجد أصناف البشر يتناول بعضهم بعض المأكولات من حيوان ونبات، ويترك بعضهم ذلك البعض. فمن العرب من يأكل الضب واليربوع والقنافذ، ومنهم من لا يأكلها. ومن الأمم من يأكل الضفادع والسلاحف والزواحف ومنهم من يتقذر ذلك، وأهل مدينة تونس يأبون أكل لحم أنثى الضأن ولحم المعز، وأهل جزيرة شريك يستجيدون لحم المعز، وفي أهل الصحاري تستجاد لحوم الإبل وألباها، وفي أهل الحضر من يكره ذلك، وكذلك دواب البحر وسلاحفه وحياته. والشريعة أوسع من ذلك كله فلا يقضي فيها طبع فريق على فريق. والمحرمات فيها من الطعوم ما يضر تناوله بالبدن أو العقل كالسموم والخمور والمخدرات كالأفيون والحشيشة المخدرة، وما هو نجس الذات بحكم الشرع، وما هو مستقذر كالنخامة وذرق الطيور وأوراث الأنعام، وما عدا ذلك لا بحد فيه ضابطاً للتحريم إلا المحرمات بأعياها. وما عداها فهو في قسم الحلال لمن شاء تناوله. والقول بأن بعضها حلال دون بعض بدون نص ولا قياس هو من القول على الله بما لا يعلمه القائل، فما الذي سوغ الظبي وحرم الأرنب، وما الذي سوغ السمكة وحرم حية البحر، وما الذي سوغ الجمل وحرم الفرس، وما الذي سوغ الضب 
والقنفذ وحرم السلحفاة، وما الذي أحل الجراد وحرم الحلزون، إلا أن يكون له نص صحيح، أو نظر رجيح، وما سوى ذاك فهو ريح."11

وما قيل في بجال المطعومات يقال في سائر المجالات وكافة التصرفات والمعاملات، لا تحريم إلا ما حرمه الله باسمه أو حرمه بصفته (الخبائث والمضار)، ولا تقييد إلا من طريق معقول ومصدر مشروع. وبسبب ما خيم على هذه القاعدة من تشكيك وتشويش نظري، ومن إغفال أو إهمال عملي، فقد أصاب المسلمين عنت كبير، في فكرهم وفقهام وحياتم. ففي بجال المكاسب والمهن والمعاملات المالية -وقد جد منها في حياة المسلمين، في ديارهم وفي غير

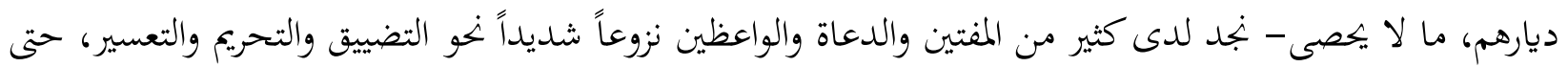
ليبدو أن القاعدة عندهم هي أن الأصل في الأشياء التحريم، وأن كل جديد فهو متهم. ويحسبون أن هذا قوة في العلم، وقوة في الدين، وقوة في التقوى، وما هو إلا ضعف في النظر، وضعف في التمييز، وضعف في التحرر الفكري. وقد أدى هذا النظر المقلوب إلى حرمان المسلمين في مشارق الأرض ومغارهما مما لا يكصى من فرص الكسب والإنتاج والتطور والتقدم والتأثير والتغيير، في البمالات الاقتصادية والسياسية والمهنية والتعليمية والإعلامية والفنية، وسائر مجالات الحياة. فكان شأن هؤلاء المفتين أشد وأسوأ من أولئك الذين قال عنهم ابن القيم: "أفسدوا بذلك كثيراً من معاملات الناس وعقودهم وشروطهم بلا برهان من الله. ومعلوم أنه لا حرام إلا ما حرمه الله ورسوله، ولا تأثيم إلا ما أتخ الله ورسوله به فاعله."12

وأختم هذه القاعدة بذكر هذا الأنموذج. فقد كنت سنة 1997 في بلد عربي، وتحدثت مع بعض قادة الحركة الإسلامية هناك عن الانتخابات البرلمانية التي كانت وشيكة في المغرب، فسألني أحدهم: هل سترشحون نساء منكم؟ قلت: نعم. فقال متعجباً (أو ربما مستنكرا): وهل عندكم فتوى تبيح لكم ذلك؟ فقلت له: نحن سنرشح النساء، وإذا كانت عندكم فتوى تحرم ذلك فابعثوا بها إلينا لننظر فيها وفي دليلها.

ثالثاً :الأصل براءة الذمة

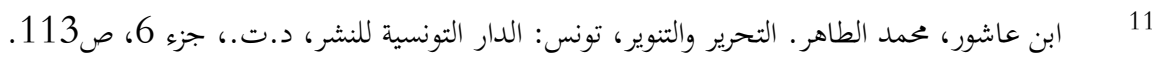

$$
\begin{aligned}
& 12
\end{aligned}
$$


هذه القاعدة هي شقيقة القاعدة السابقة، أو هي الوجه الآخر لها. وهي تعني أن ذمة الإنسان بريئة خالية من أي حق عليها أو تكليف يلزمها، حتى يثبت شيء من ذلك بدليله وحقه. وحرية الناس كما تعاق وتضيق بالمرمات والممنوعات، فإها أيضاً تعاق وتضيق بالتكاليف والالتزامات. فلهذا كانت أصالة الحرية محمية من ضائقة التحريم بالإباحة الأصلية، ومحمية من ضائقة الإلزام بالبراءة الأصلية. فلا تحريم إلا بدليل ولا إلزام إلا بدليل. وفي هذا المعنى يقول ابن القيم "لا واجب إلا ما أوجبه الله، ولا حرام إلا ما حرمه الله، ولا دين إلا ما شرعه الله."13

وأصل هذه الأصول في الإسلام، هو أن الناس كلهم عباد متساوون، فلا يحق -في الأصل- لأحدهم أن يتحكم في غيره وأن يقيد حريته. بل الأصل أن من يتحكم في العباد ويقيد حرية العباد هو رب العباد. وأما غيره فإن مارس شيئاً من ذلك، فيجب أن يكون بالتبعية وفي حدود ما هو مأذون ومشروع من صاحب الحق الأصلي. فهو سبحانه لا يمكن أن يحيف أو يتعسف على أحد.

يقول العلامة ابن عاشور: "وإن موقف تحديد الحرية موقف صعب وحرج ودقيق على المشرع غير المعصوم، فواجب ولاة الأمور التريث وعدم التعجل، لأن ما زاد على ما يقتضيه درء المفاسد وجلب المصالح الحاجية من تحديد الحرية يعد ظلماً."14 وقال في موضع آخر: "واعلم أن الاعتداء على الحرية نوع من أنواع الظلم."15

ومما استدل به ابن حزم على تأصيل هذا الأصل حديث أبى هريرة عن النبي صلى الله عليه وسلم "دعوني ما تركتم، إنما هلك من كان قبلكم بسؤالهم واختلافهم على أنبيائهم. فإذا غيتكم عن شيء فاجتنبوه، وإذا أمرتكم بأمر فأتوا منه ما استطعتم". 16 قال ابن حزم: "فهذا حديث جامع لكل ما ذكرنا، بـان بين فيه عليه السلام أنه إذا فهى عن شيء فواجب أن يجتنب، وأنه إذا أمر بشيء فواجب أن يؤتى منه ما بلغت الاستطاعة، وإن ما لم ينه عنه ولا أمر به فواجب أن لا يبحث عنه في حياته عليه السلام. وإذ هذه صفته ففرض على كل مسلم أن لا يحرمه ولا يوجبه."17

$$
\begin{aligned}
& 13 \\
& 14 \\
& 15 \text { } 15 \\
& 16 \\
& 17 \text { (بن حزم، الإحكام في أصول الأحكام، مرجع سابق، جزء 8، لـ } 316
\end{aligned}
$$


وبناء على هذه القاعدة -قاعدة البراءة الأصلية- لا يصح ولا يجوز لأحد من الناس وضع عبادات أو الزيادة في عبادة وضعها الشارع، أو الزيادة في شروطها وصفاتا.

ويدخل في هذا أول ما يدخل، الابتداع في الدين. فكل بدعة ضلالة وكل ضلالة في النار. والابتداع نوع من

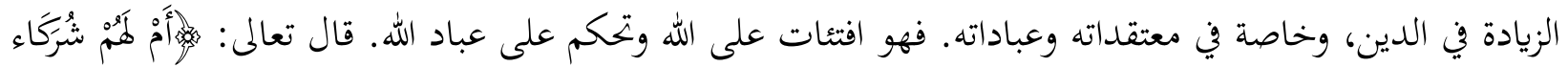

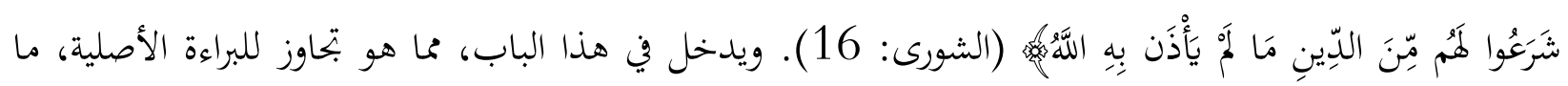
يضعه بعض الفقهاء من شروط إضافية لبعض الأحكام والتكاليف الشرعية، سواء كانت في العبادات أو المعاملات أو غيرها. وقد كان الإمام مالك رحمه الله ينفر من إلزام الناس بما لم يرد في كتاب ولا سنة ولا جرى به العمل عند الصحابة رضي الله عنهم. قال ابن القصار في مسألة استصحاب البراءة الأصلية "ليس في ذلك عن مالك رحمه الله نص، ولكن مذهبه يدل عليه، لأنه احتج في أشياء كثيرة سئل عنها فقال: لم يفعل النبي صلى الله عليه وسلم ذلك ولا الصحابة رحمة الله عليهم. وكذلك يقول :ما رأيت أحداً فعله. وهذا يدل على أن السمع إذا لم يرد بإيجاب شيء لم يجب، وكان على ما كان من براءة الذمة."18 ومن مقتضيات هذه القاعدة أيضاً أن الناس أحرار في أمواهم وممتلكاقم، لا يفرض عليهم شيء ولا يؤخذ منهم شيء إلا بدليل وبطريق مشروع ولاعتبارات راجحة ومقدمة.

خاتمة:

وبعد، فقد ركزت في هذا المقال على الحرية في أصولها وأسسها الفكرية وفي أبعادها المنهجية. وقد نزعت في حديثي إلى هذه الناحية: أولاً لما هو معلوم من كون الحرية في بجالاتما وقضاياها السياسية والاجتماعية حاضرة بقوة وبكثافة فيما يقال ويكتب عن الحرية. فلعلي بهذا الاختيار أكون مسهماً في إعادة التوازن وإعادة الاعتبار إلى ما تناولته. وثانياً لإيماني بأن الحرية الباطنية، حرية النفس والفكر والضمير، هي التي تصنع باقي الحريات، وهي التي تغذيها وتحميها. فإزاحة الغبار والصدأ عن مبدأ أصالة الحرية وفطريتها هي بمثابة تجديد لإيمان الإنسان بنفسه وبكقيقته وبما وهبه خالقه. وإزالة التشكيك والتأرجح في الإباحة الأصلية والبراءة الأصلية، هي إهاء لحالة التكبيل والاعتقال ورفع للآصار والأغلال، عن فكرنا وفقهنا وإبداعنا. وكل ذلك في نطاق المشروعية الواضحة والعقلانية الصحيحة، وفي ظل الشعور بالأمانة والمسؤولية.

$$
18 \text { بن بن القصار، أبو الحسين. المقدمة في الأصول، تحقيق وتعليق محمد الحسين السليماني، بيروت: دار الغرب الإسلامي، } 1996 .
$$

